\title{
Mapping Perception of Place through Emotion, Memory, Senses, and the Imaginary
}

\author{
Joanna Gardener ${ }^{\mathrm{a}, \mathrm{b}} *$, William Cartwright ${ }^{\mathrm{b}}$, Lesley Duxbury ${ }^{\mathrm{b}}$, Amy Griffin $^{\mathrm{b}}$ \\ ${ }^{a}$ Swinburne University of Technology, jgardener@swin.edu.au \\ ${ }^{b}$ RMIT,william.cartwright@rmit.edu.au, lesley.duxbury@rmit.edu.au,amy.griffin@rmit.edu.au \\ * Corresponding author
}

Keywords: Mapping, Design, Art, Place, Perception, Senses, Emotion, Memory

Themes: T1. Art and Cartography, T6. Cognitive Issues in Geographic Information Visualization, T13. Map Design

\begin{abstract}
:
This paper reports on a research project that has a focus on the perception of place, collective experience, and shared perceptions. It aims to demonstrate how mapping can be used to bring depth and meaning to places through portraying emotions, memory, sensation, and the imagination. This study explores how maps can be developed to create a deeper understanding and explore perceptions of place. It draws upon the diverse experiences of a participatory study of a single, shared place, the Edinburgh Gardens in North Fitzroy, Melbourne, Australia. This participatory study expands upon a previous research study of the Edinburgh Gardens, which focused on the influence of time in the perception of place. While time plays a significant role in changing perceptions of place, emotions, sensory inputs, and memory also play vital roles in shaping these perceptions.
\end{abstract}

The intent of this study was to look for shared experiences, synergies, or differences between different participants' visits to the park, while examining how people perceive, move through, and understand the place and their emotional connection to it. Through a three-part participatory study, 1. Memory, 2. Experience, and 3. Reflection, the data collected informs a series of emotional maps of the Edinburgh Gardens.

The first part of the study, Memory, asked participants to recall and describe a memory of an experience they had at the Edinburgh Gardens. Questions included why the event was significant, were they with other people, how long did they stay, and could they remember any smells or sounds or think of any colours associated with the experience. Participants were also asked to draw a map of the gardens as they remembered them (Figure 1). The second part of the study, Experience, asked participants to go for a walk in the park and capture their experience in real-time (Figure 2). This included many of the same questions as Part 1, while also asking them to record their route as they moved through the park, via a GPS walking app and pen and paper (Figure 3). The final part of the study, Reflection, asked participants to reflect and compare the visits to the park.
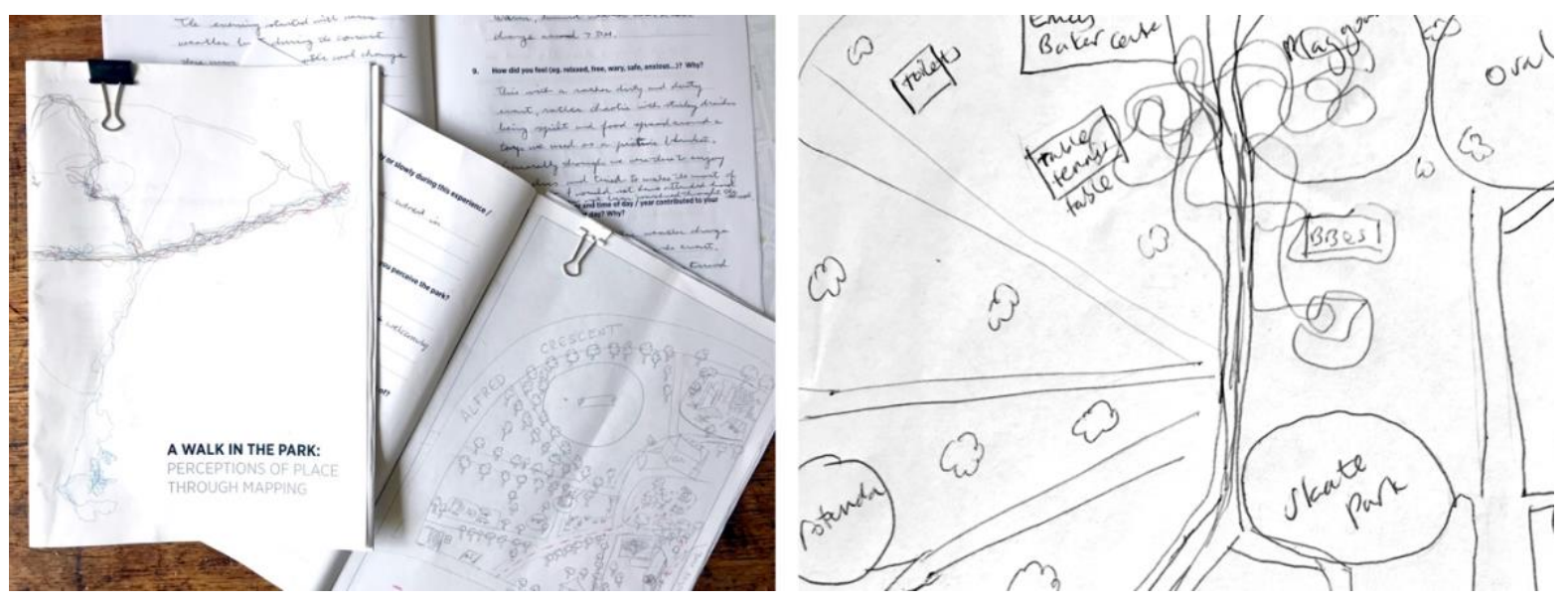

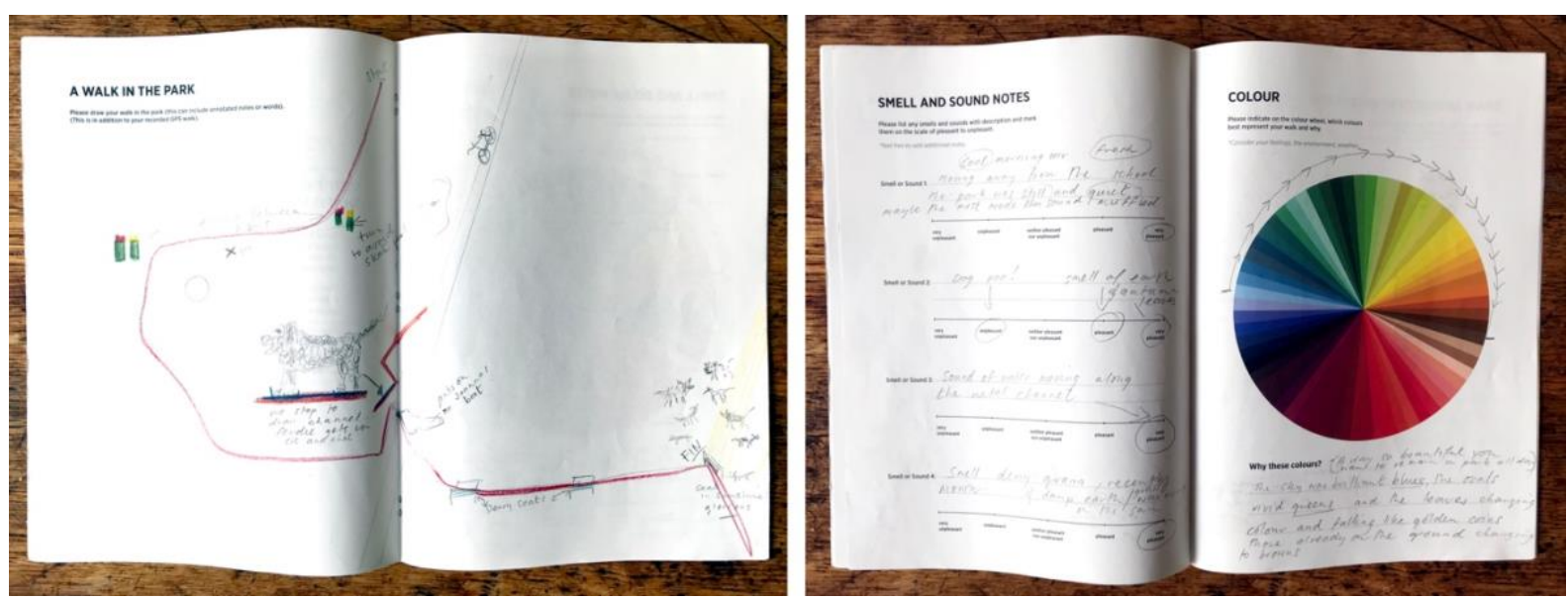

Figure 2. Pages from Participatory Study, Part 2. Experience, Joanna Gardener, 2018
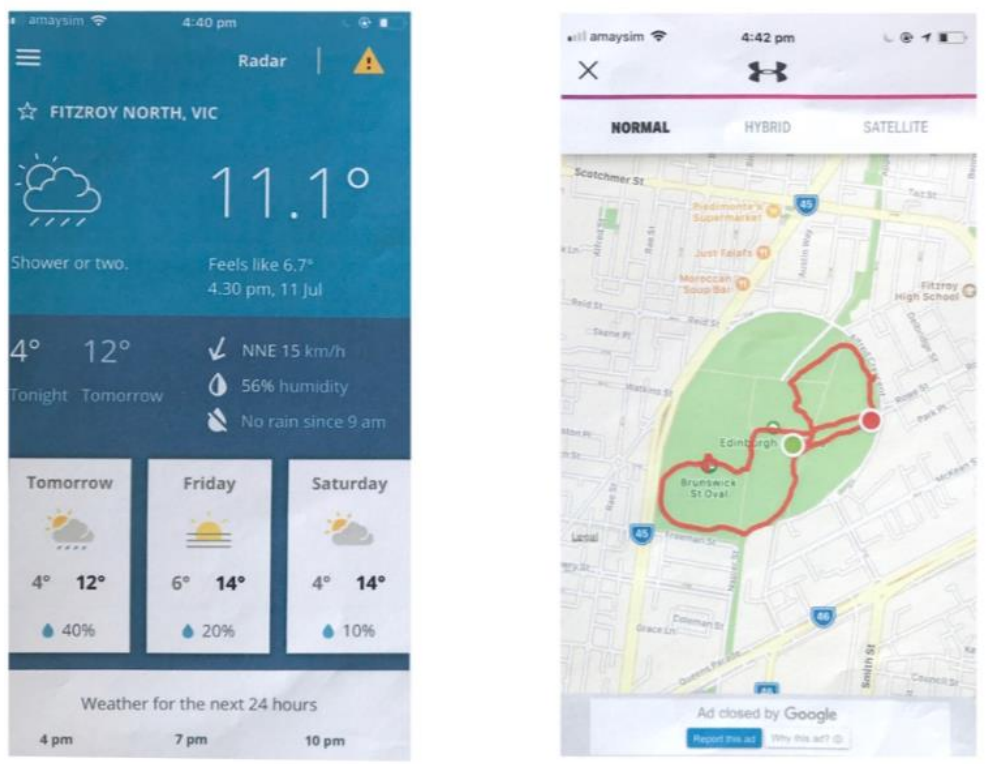

Figure 3. Example of data collection from Participatory Study, Part 2. Experience, Joanna Gardener, 2018

The intention of this participatory component of the research programme is to visually explore emotional connections to place by creating prototype maps of place perceptions. The study focuses on the making of place and examines how places are perceived through deep mapping and associated spatial narratives. In creating these prototype maps, it investigates how the cartographic sciences, design thinking, and artistic expression can inform one another to spark new ideas and generate new ways of thinking about approaches to cartography and in turn, the possibilities that emerge when these disciplines work together.

Through a practical and theoretical investigation into emotional cartography, this study explores perception of place and the representation of shared perceptions through mapping. Furthermore, it illustrates the role memory and conscious experience have on feelings and emotions attached to perception of place. Through creating prototypes of emotional maps, we are able to see the crossover between scientific cartography and artistic expression and appreciate how these different disciplines can be engaged to shape new approaches to cartography and reveal the map's ability to impart emotion and evoke a sense of place. 